\title{
A model of the dynamics of boundary film formation
}

\author{
Sung-H. Choa ${ }^{\mathrm{a}}$, Kenneth C. Ludema ${ }^{\mathrm{a}, *}$, Gregg E. Potter ${ }^{\mathrm{b}}$, Benjamin M. DeKoven ${ }^{\mathrm{b}}$, \\ Ted A. Morgan ${ }^{\mathrm{b}}$, Kishore K. Kar \\ "Department of Applied Mechanics and Mechanical Engineering. The University of Michigan, Ann Abor, MI 48109, USA \\ ${ }^{\mathrm{b}}$ The Dow Chemical Co., Midland, MI 48667, USA
}

Received 18 October 1993; accepted 1 June 1994

\begin{abstract}
The dynamics of formation and loss of the boundary films formed during sliding on steel surfaces were investigated over a range of temperature. Tests are performed on a cylinder-on-disk machine using mineral oil with various concentrations of zinc dialkyldithiophosphate (ZDP). The thickness and refractive index of the boundary films during step load test were monitored in situ with an ellipsometer, and the composition of the films was analyzed by X-ray photoelectron spectroscopy (XPS). As temperature increases, chemical reactivity increases the film formation rate, while the film removal rate increases owing to (a) the decrease of durability of the boundary film material and (b) the reduction of hydrodynamic fluid film thickness due to decreasing viscosity of the lubricant. There is a balance between these two competing mechanisms, and this balance is reflected in the boundary film thickness. The boundary films consist of a film of oxide and metallic compound (OMM) covered by an organo-iron compound (OIC). Their relative effectiveness in preventing scuffing depends on temperature and composition. In particular, the OIC is effective in reducing wear of the opposing surfaces by covering the OMM.
\end{abstract}

Keywords: Boundaries; Dynamics

\section{Introduction}

In lubricated sliding, the importance of boundary films or protective films has been recognized for decades. Since these films directly affect friction and wear phenomena, several attempts have been made to develop the proper model to describe their formation dynamics and properties. Boundary films appear to be particularly important in preventing or postponing scuffing, the unexpected and catastrophic type of failure of lubricated surfaces sometime early in the life of the components. To form the protective films, compounds containing one or more of the elements sulfur, chlorine, phosphorous, boron, iodine, etc., are added to liquid lubricants. Some lubricants such as mineral oils, which often contain sulfur and oxygen, form the boundary films without deliberate addition of reactive elements.

Zinc dialkyldithiphosphate (ZDP) is a compound that has been extensively used as an extreme-pressure or anti-wear additive in engines and gears. It is well established that ZDP reacts with metal surfaces to form

*Corresponding author. a thick and easily shearable film on the surfaces, thus reducing friction and preventing scuffing. The study of ZDP-induced films has generally focused on analyzing film composition, and correlating those species with load-bearing performance $[1,2]$, with wear mechanisms $[3,4]$ or with possible reaction kinetics $[5,6]$. However, since the film formed is likely a complex mixture, possibly composed of non-stoichiometric compounds, the results among various authors are generally inconclusive and sometimes differ significantly. For example, many different results and assumptions have been reported concerning the influence of the concentration of sulfur and phosphorus in the additive-induced films on antiwear or extreme-pressure performance $[7,8]$.

A variety of views have been expressed regarding the composition of the surface layer. Godfrey [9] proposed the formation of iron oxide (mainly $\mathrm{Fe}_{3} \mathrm{O}_{4}$ ) and iron sulfide. Baldwin [10] proposed the formation of metal sulfides. Bird and Galvin [11] proposed the formation of polymeric films containing zinc, phosphorus and sulfur. Watkins [12] proposed zinc polyphosphate and iron sulfide formation. As a part of previous work, Kang and Ludema [13] found that the protective film 
which forms upon surface sliding in mineral oil was a soft and durable $\mathrm{Fe}_{3} \mathrm{O}_{4}$. Since the ZDP action is very sensitive to temperature and possibly pressure, those diverse findings may result from different reaction mechanisms limited to specific operating conditions. In fact, besides film composition, the film thickness and dynamics of film formation and removal are considered to be crucial in controlling scuffing $[14,15]$. Recently, Çavdar and Ludema [16] found that the films formed in lubricated sliding included $\mathrm{Fe}_{3} \mathrm{O}_{4}$ and metallic iron, over which is a soft organo-iron compound layer. This organo-iron compound is mechanically weak when formed from plain mineral oil, and is strong and durable when formed from oils containing ZDP. Ludema and co-workers did their work at room temperature; this was useful for identifying the effects of materials, surface roughness, material hardness, loading rate and other variables, but it did not allow a study of the effect of lubricant type, additive concentration and film durability under realistic conditions of oil use.

The main purpose of this present research is to extend the previous work to higher temperature, and consequently to obtain a better understanding of the mechanisms of boundary lubrication. Also, the boundary films formed at high temperatures are characterized.

\section{Experimental details}

As in previous work, the tests were carried out with a cylinder-on-disk sliding machine. The schematic configuration of this friction machine is shown in Fig. 1. A cylinder $6.35 \mathrm{~mm}$ long and $6.35 \mathrm{~mm}$ in diameter is mounted in a cylinder holder and pressed against the disk specimen on a rotating plate by a dead weight. The disk specimen, which is $50.8 \mathrm{~mm}$ in diameter and $4 \mathrm{~mm}$ thick, is driven by a d.c. motor.

The cylinder was taken from a rolling bearing made of 52100 steel (hardness $58 \mathrm{HRC}$ ), and had been crowned to prevent an edge effect during sliding. The initial surface roughness $R_{\mathrm{a}}$ in the longitudinal direction is $0.02-0.025 \mu \mathrm{m}$. Disk specimens were made of 4340

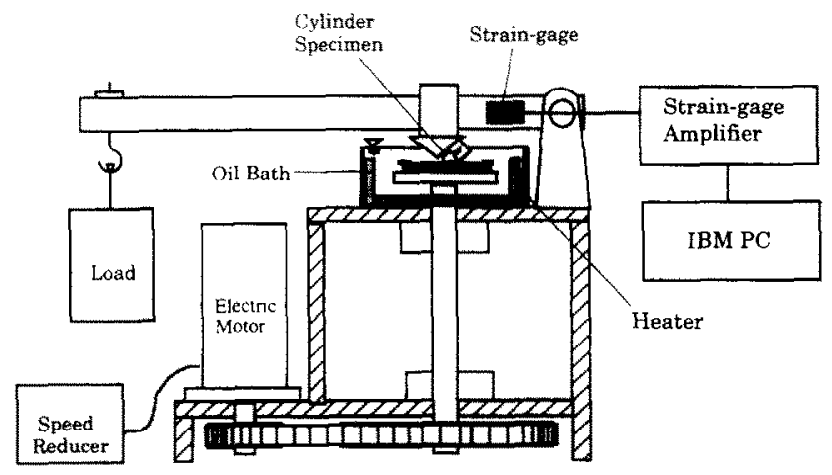

Fig. 1. Cylinder-on-disk friction machine. steel having a hardness of $55 \mathrm{HRC}$. These steel flats were ground with $\mathrm{SiC}$ sandpaper and then polished with diamond compound to a final roughness $R_{\mathrm{a}}$ of $0.025-0.03 \mathrm{~mm}$. After polishing, the disks were ultrasonically cleaned in acetone, followed by rinsing in isopropyl alcohol.

White paraffinic (mineral) oil of viscosity of $25.3 \mathrm{cSt}$ at $40^{\circ} \mathrm{C}$ was used as the lubricant. ZDP was added in various concentrations to the paraffinic oil in order to observe the effect of additive concentrations on the boundary film formation, particularly on the reactivity and durability of the boundary film. Concentrations of $0.5,1$ and 2 wt. \% ZDP were chosen so as to be near to the customary concentration of ZDP in automobile engine oils (about 1 wt.\%).

All the experiments were carried out in air atmosphere. The oil was heated with a tubular heater located inside the bath. The temperature of oil was controlled by an Omega, Inc. model CN9000 temperature controller with an accuracy of $\pm 0.5^{\circ} \mathrm{C}$. The sensor for the controller, a chromel-constantan thermocouple, was located at the same height as the contact surface. Temperature was generally raised in increments of 50 ${ }^{\circ} \mathrm{C}$ from $50{ }^{\circ} \mathrm{C}$ to a point below the flash temperature of the each lubricant, or to the point where degradation (sludging and darkening) of the lubricant began. Before each test, the apparatus was washed several times with acetone, and then the oil bath was filled with new lubricant. The friction force was continuously recorded during the test. The test ended when there was excessive vibration and the friction coefficient increased sharply. This was taken to be an indication of scufting.

The standard test conditions were identical with previous tests [16]: a sliding speed of $0.06 \mathrm{~m} \mathrm{~s}^{-1}$ and step loading with increments of approximately $62.5 \mathrm{~N}$ every $10 \mathrm{~min}$ (for some steps, $70 \mathrm{~N}$ was used). This step loading sequence was used in order to shorten the time to build up the boundary films of interest.

The thickness and refractive index of the films formed on the disk surface were measured in situ with a Mueller Matrix Ellipsometer. Its theory and design are described in Refs. [17] and [18]. Fig. 2 shows the configuration of the circular sliding wear track and ellipsometer used in the experiment. The overall procedure for ellipsometric measurement in this experiment is also identical with that of previous tests [16], except that previous tests were all done at $20^{\circ} \mathrm{C}$. The ellipsometric measurcments were taken, under an oil bath at several angles of incidence between $60^{\circ}$ and $70^{\circ}$, when the machine was stopped to increase the load (every 10 $\mathrm{min}$ ). Neither the cylinder nor the disk specimen was removed from its original position during measurement.

The chemical composition and state of the boundary film formed on the disk surface were analyzed using X-ray photoelectron spectroscopy (XPS). After fabrication, samples were stored with excess oil intentionally 


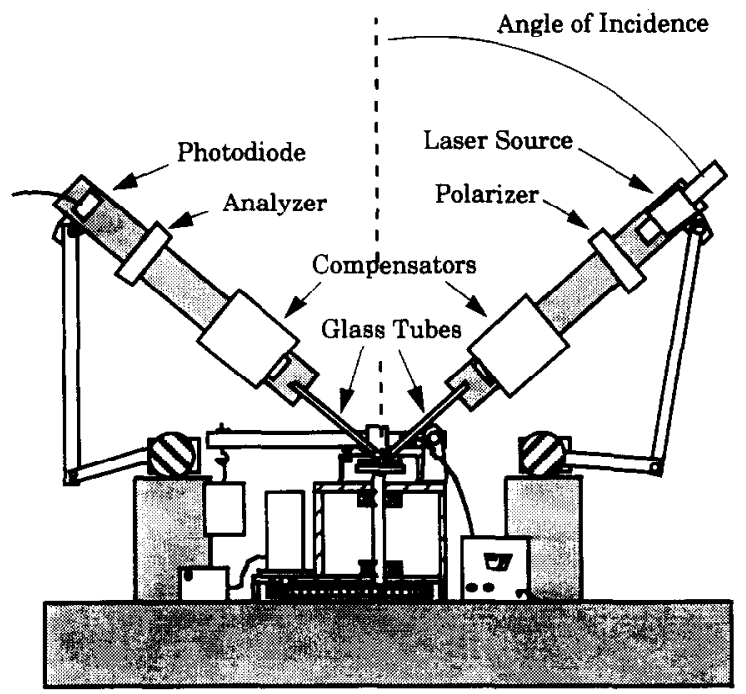

(a)

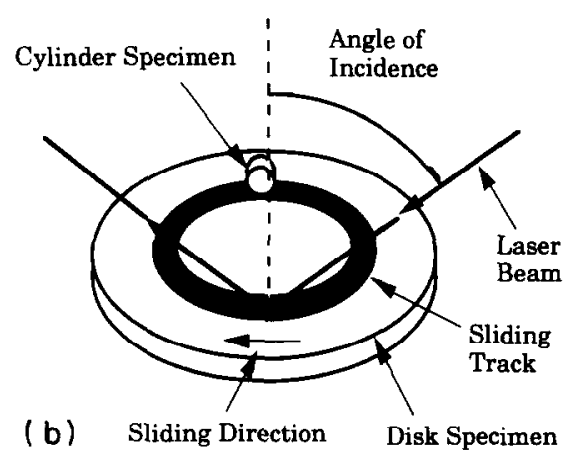

Fig. 2. (a) Experimental set-up and Automated Mueller Matrix Ellipsometer (reprinted from Çavdar and Ludema [16]). (b) Enlarged view of the sliding surface in the oil bath (reprinted from Çavdar and Ludema [16]).

left on the surface until just before introduction into vacuum for XPS analysis. The oil was removed by rinsing twice in hexane to remove any lubricant but leave other organic residues on the sample surface. Note that it is difficult to determine whether or not the rinsing procedure removed any of the organic residue of interest. The rinsing procedure selected here is a reasunable compromise between removing the oil layer and leaving the tribofilm intact.

All surface analyses were performed on a Surface Science Instruments Model S Probe X-ray photoelectron spcctrometer equipped with a monochromatic $\mathrm{Al} \mathrm{K}_{\mathrm{a}}$ $\mathrm{X}$-ray source. XPS analyses were performed on the wear scar area. Surface element fractions werc determined by first observing which elements were present with a survey spectrum, then acquiring individual region spectra for the elements observed. Peak areas were then determined for each element and corrected using sensitivity factors determined for the instrument used. Experimental conditions for the survey and multiplex spectra are outlined in Table 1 . In all of the XPS analyses, no charge compensation was required. The XPS spectrometer was calibrated so that the $\mathrm{Au}$ $\left(4 \mathrm{f}_{7 / 2}\right)$ photoline occurred at $84.0 \mathrm{eV}$.

For XPS sputter depth profiles, XPS multiplex and individual region spectra were acquired at intervals with alternating sputtering and data acquisition on the $2 \% \mathrm{ZDP}, 150^{\circ} \mathrm{C}$ sample. Bombardment of the sample surface was carried out with $4 \mathrm{keV} \mathrm{Ar}^{+}$using a Perkin-Elmer Physical Electronics (PHI) model 04-303 ion gun. A Mo mask with a hole of about $5 \mathrm{~mm}$ diameter was used to define the bombarded area. The atom fractions were determined as outlined above. This sample was chosen since ellipsometry indicated that wear under these conditions formed the thickest tribofilm. Note that the analysis was performed at the end of the wear trial $(1101 \mathrm{~N})$, where the film thickncss as measured by ellipsometry was approximately $300 \AA$, not at the point in the trial when the thickness of the wear film was observed to be largest. Analytical conditions for the depth profiles are also shown in Table 1.

The sputter rate for these analyses was determined by sputtering an area away from the wear scar (which was considerably less rough) and measuring the etch step as defined by the Mo mask with a Tencor Instruments Alphastep 300 stylus profilometer. This sputter rate was determined to be $20.9 \AA \min ^{-1}$. The assumption here is that the etch rate observed for an area away from the wear scar (predominantly substrate steel) is representative of the sputter rate for an area on the wear scar.

The wear scar widths on the cylinder were measured with an optical microscope for selected lubricants.

Table 1

XPS analysis conditions

\begin{tabular}{|c|c|c|}
\hline \multirow[t]{2}{*}{ Parameter } & \multicolumn{2}{|c|}{ XPS analysis } \\
\hline & Wide scan & $\begin{array}{l}\text { Individual } \\
\text { photoline }\end{array}$ \\
\hline$X$-ray spot size & \multicolumn{2}{|c|}{$150 \times 800 \mu \mathrm{m}$} \\
\hline Source & \multicolumn{2}{|c|}{$\mathrm{Al} \mathrm{K \alpha}$} \\
\hline Chamber pressure (torr) & \multicolumn{2}{|c|}{$2 \times 10^{-9}$} \\
\hline Pass energy & $150 \mathrm{eV}$ & $50 \mathrm{eV}$ \\
\hline Energy resol. $\mathrm{Ag}\left(3 \mathrm{~d}_{5 / 2}\right)$ & $1.4 \mathrm{eV}$ & $0.72 \mathrm{eV}$ \\
\hline Sampling voltage/step & $0.5 \mathrm{eV}$ & $0.05 \mathrm{eV}$ \\
\hline & \multicolumn{2}{|c|}{ Sputter profile conditions } \\
\hline Sputter species, energy & \multicolumn{2}{|c|}{$\mathrm{Ar}^{+}, 4 \mathrm{keV}$} \\
\hline Current density $\left(\mathrm{mA} \mathrm{cm}^{-2}\right)$ & \multicolumn{2}{|c|}{$50-100$} \\
\hline Incidence angle (surface) & \multicolumn{2}{|c|}{$35^{\circ}$} \\
\hline Sputter raster size $(\mathrm{mm})$ & \multicolumn{2}{|c|}{$6 \times 6$} \\
\hline Sputter time/point (mm) & \multicolumn{2}{|c|}{4} \\
\hline Total sputter time (min) & \multicolumn{2}{|c|}{40} \\
\hline
\end{tabular}




\section{Results}

The matrix of test samples and wear temperatures consisted of plain mineral oil at 50,100 and $150^{\circ} \mathrm{C}$, mineral oil with 0.5 wt.\% ZDP at 100 and $150{ }^{\circ} \mathrm{C}$, mineral oil with $1 \mathrm{wt} . \% \mathrm{ZDP}$ at 100 and $150{ }^{\circ} \mathrm{C}$, and mineral oil with 2 wt.\% ZDP at $50,100,150$ and 200 ${ }^{\circ} \mathrm{C}$. The loadings ranged from 0 to approximately 1200 $\mathrm{N}$, with the end point determined by the load at which the onset of scuffing occurred.

\subsection{Film thickness}

The boundary film formed over a range of temperature exhibited differences in the initial film growth rate, maximum film thickness achieved, and final film decay time and rate.

For plain mineral oil, the changes in boundary film thickness during a step loading test at four temperatures are shown in Fig. 3. The previous test results of Çavdar and Ludema [16] at room temperature $\left(20^{\circ} \mathrm{C}\right)$ are shown with a dashed line. Two major changes in film thickness variation can be seen as temperature increases. First, the films at higher temperatures grow somewhat thicker overall than those at room temperature. The thickest film using plain mineral oil was formed at 50 ${ }^{\circ} \mathrm{C}$, which reached its maximum thickness of $150 \AA$ at $390 \mathrm{~N}(60 \mathrm{~min})$. Second, as temperature increased, the films grew at similar rates, but began to diminish in thickness earlier, i.e. at lower load. No measurements of plain mineral oil were made at $200{ }^{\circ} \mathrm{C}$ because of severe degradation of the lubricant.

For mineral oil containing ZDP, the changes in film thickness are more complicated than those of plain mineral oil. The initial film growth rate and maximum film thickness generally increase as temperature or concentration of ZDP increases. The final film decay time and rate are different for each case.

For $2 \% \mathrm{ZDP}$, the change in the film thickness with applied load (time) is presented in Fig. 4, at four temperatures from 50 to $200^{\circ} \mathrm{C}$, including room-temperature results [16]. At $50^{\circ} \mathrm{C}$ the film is very thin, and changes in thickness with increasing load are similar to those at room temperature. However, as temperature increases to 100 and $150^{\circ} \mathrm{C}$, the films grow much faster and become thicker near the begiming of sliding, to around $860 \AA$, and then decay rapidly with increasing load, at about $265 \mathrm{~N}(40 \mathrm{~min})$. At $150{ }^{\circ} \mathrm{C}$, the film thickness fluctuates with increasing load (between about 500 and $100 \AA$ ). At $200^{\circ} \mathrm{C}$, the film remains thin, and scuffing begins after just a few step load increments. For $1 \% \mathrm{ZDP}$, the changes in film thickness at 100 and $150{ }^{\circ} \mathrm{C}$ are shown in Fig. 5. The film formed at 150 ${ }^{\circ} \mathrm{C}$ is thicker than the one at $100{ }^{\circ} \mathrm{C}$. The film at 150 ${ }^{\circ} \mathrm{C}$ became thin at around $1040 \mathrm{~N}(160 \mathrm{~min})$, with the maximum film thickness (550 $)$ ) occurring at about
Plain mineral oil

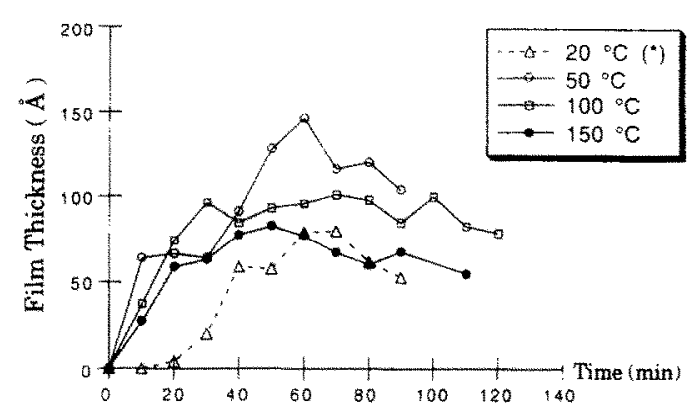

(a)
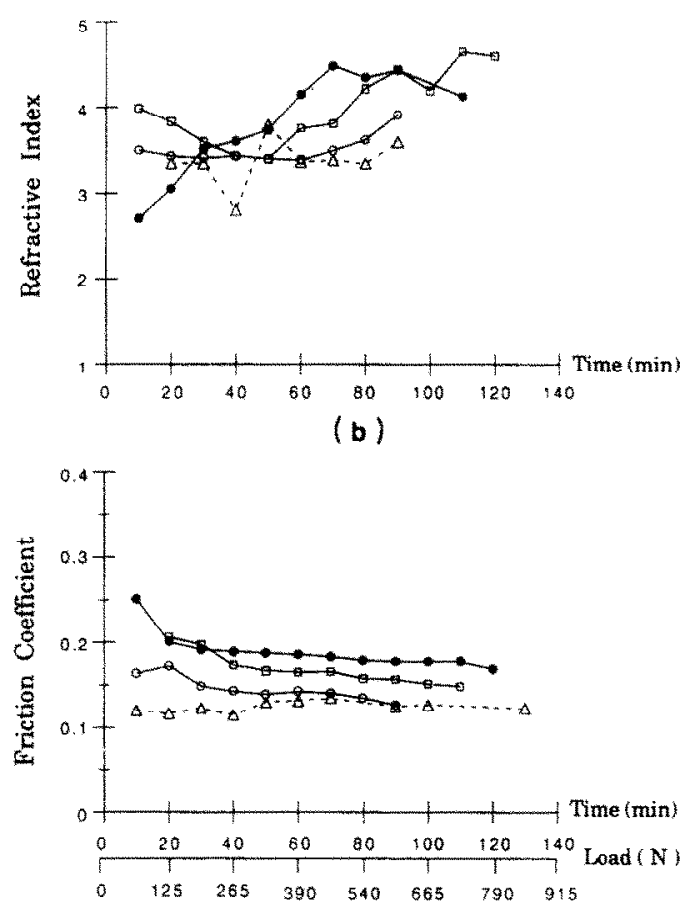

(c)

Fig. 3. Growth of boundary film in plain mineral oil with increasing loads at four temperatures $\left({ }^{*}\right.$, at room temperature $\left(20^{\circ} \mathrm{C}\right)$, reprinted from Cavdar and Ludema [16]): (a) film thickness; (b) refractive index of the film; (c) friction coefficient.

$600 \mathrm{~N}$ (90 min). For 0.5\% ZDP (Fig. 6), the film thicknesses at 100 and $150{ }^{\circ} \mathrm{C}$ are similar to those of the $1 \%$ ZDP case. However, the film formed at 150 ${ }^{\circ} \mathrm{C}$ becomes thin at $665 \mathrm{~N}(100 \mathrm{~min})$, earlier than the $1 \%$ ZDP case.

\subsection{Refractive index and appearance of the films}

The relative chemical composition of the films formed under different conditions can be estimated from appearance and measurements of the refractive index of the films, even though these methods cannot provide exact information about the composition of the films. In general, a higher refractive index likely indicates the presence of metal-containing solids, and lower values 

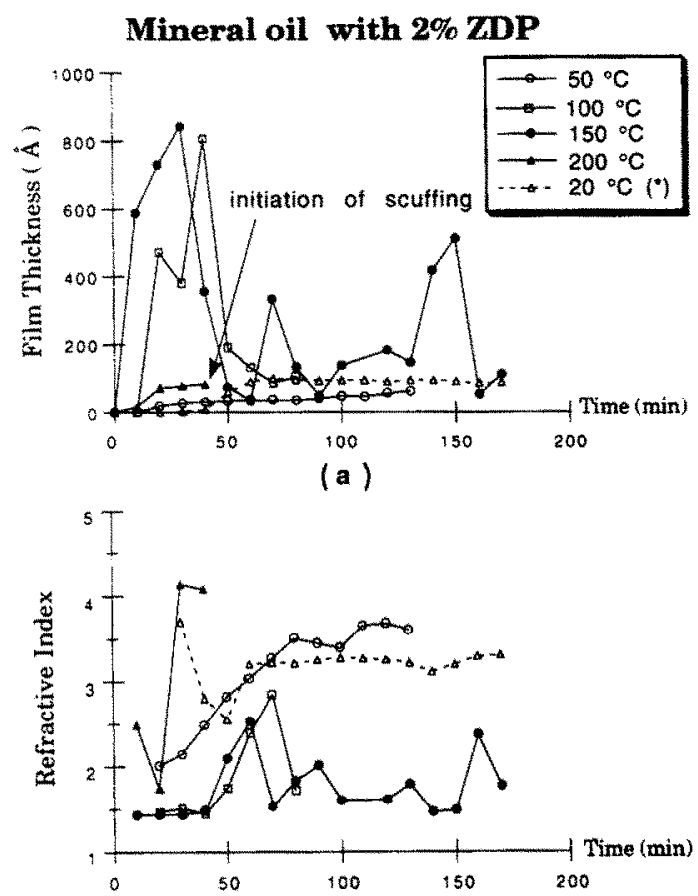

(b)

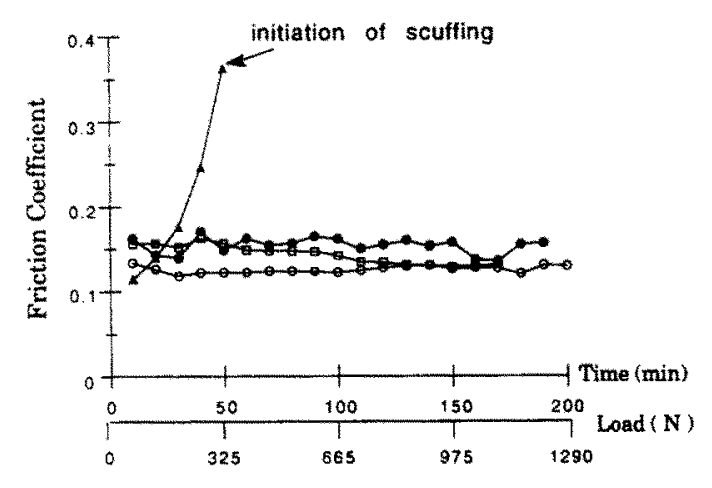

(c)

Fig. 4. Growth of boundary film in mineral oil with $2 \% \mathrm{ZDP}$ with increasing loads at five temperatures $\left({ }^{*}\right.$, at room temperature $(20$ ${ }^{\circ} \mathrm{C}$ ), reprinted from Cavdar and Ludema [16]): (a) film thickness; (b) refractive index of the film; (c) friction coefficient. Note that 20 ${ }^{\circ} \mathrm{C}$ friction data is not shown.

indicate more organic-type compounds. The values of the refractive index are shown in part (b) of Figs. 3-6.

For plain mineral oil, the refractive index of the boundary films increases gradually with increasing temperature and load. The appearance of the films shows corresponding changes, darkening to brownish-yellow with increasing load and temperature.

On the other hand, for mineral oil containing ZDP (any addition), the refractive index at high temperatures is considerably lower than that at room temperature and tends to decrease with increasing temperature, except at $200^{\circ} \mathrm{C}$ (where scuffing rapidly occurs). The values of the refractive index fluctuate with increasing load, usually reaching higher values at higher loads. The refractive index at $200{ }^{\circ} \mathrm{C}$ increases significantly

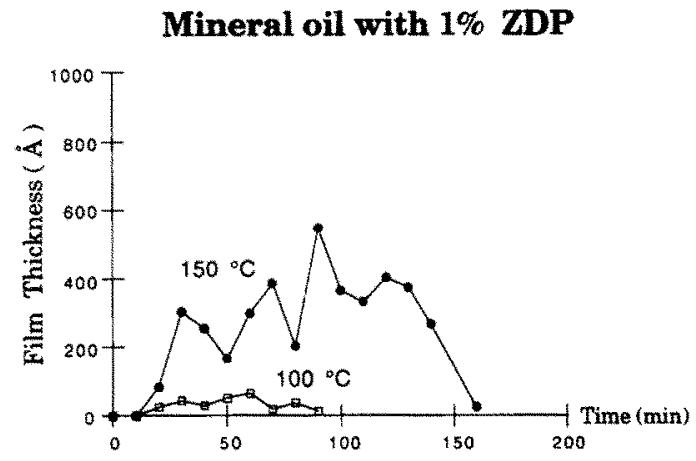

(a)

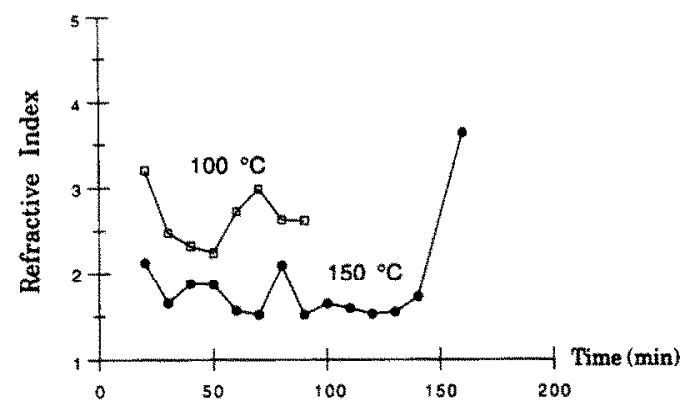

(b)

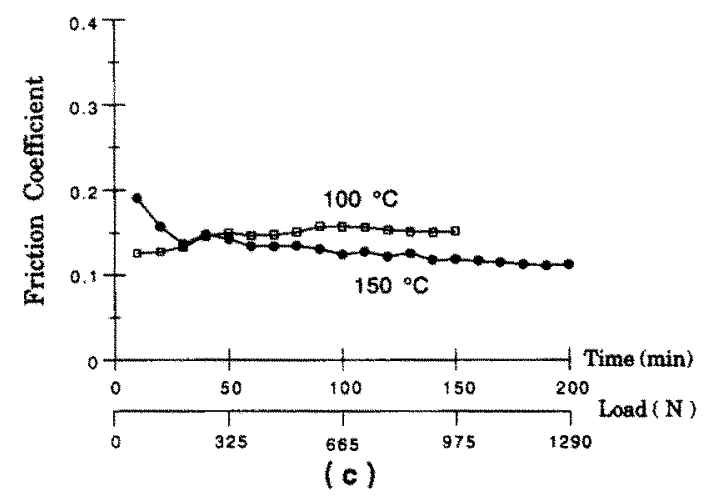

Fig. 5. Growth of boundary film in mineral oil with $1 \% \mathrm{ZDP}$ with increasing load at two temperatures: (a) film thickness; (b) refractive index of the film; (c) friction coefficient.

during the test. Also, the films formed at 50, 100 and $150^{\circ} \mathrm{C}$ are lighter in color than those of plain mineral oil, while the color of the film formed at $200^{\circ} \mathrm{C}$ is very dark and brown. The differences in terms of appearance and refractive index among the various ZDP concentrations are not as obvious.

\subsection{Friction}

The friction generally tends to increase as temperature increases (1\% ZDP is an exception). There is no clear trend, however, to the dependence of friction on load. The changes in the friction coefficient for each lubricant are shown in part (c) of Figs. 3-6.

For plain mineral oil, the friction coefficient is high at the beginning of sliding at all three temperatures. 


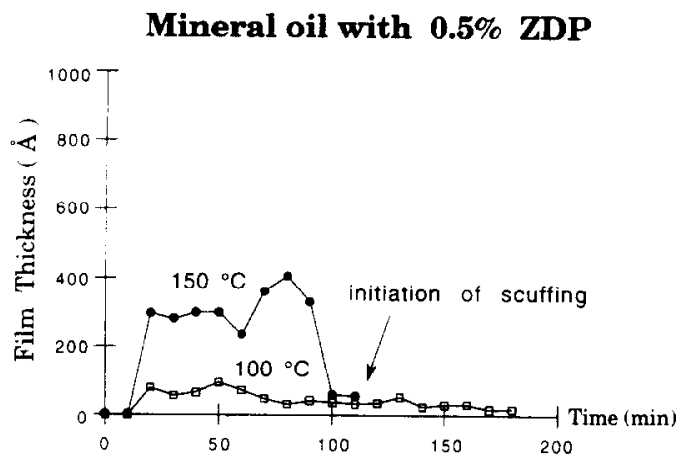

(a )

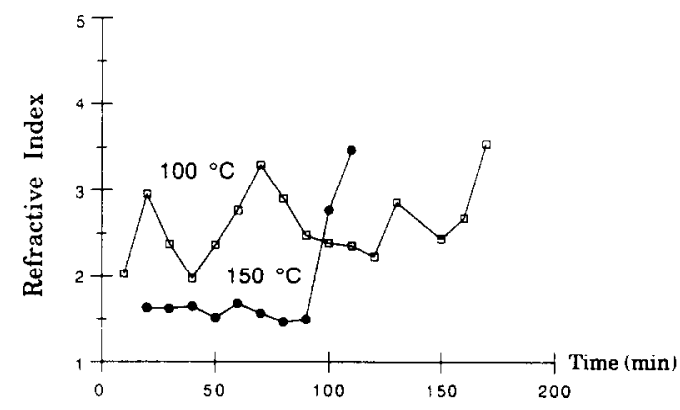

(b)

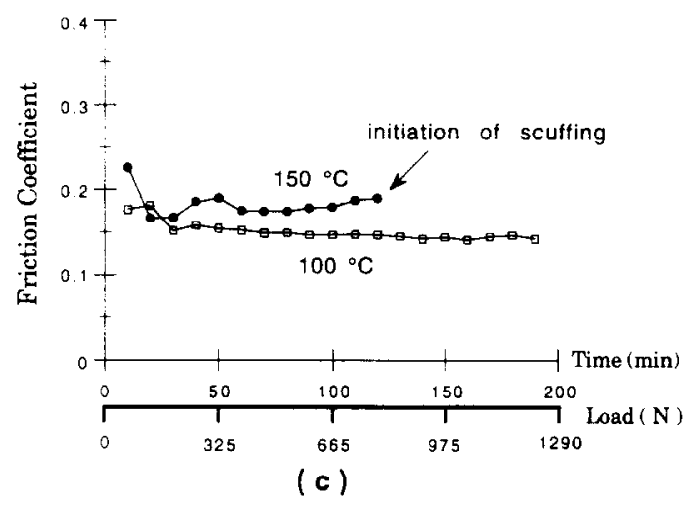

Fig. 6. Growth of boundary film in mineral oil with $0.5 \%$ ZDP with increasing load at two temperatures: (a) film thickness; (b) refractive index of the film; (c) friction coefficient.

After that, the friction decreases slightly. The overall friction coefficient increases with increasing temperature.

For mineral oil containing ZDP, the friction also increases with increasing temperature, but overall average values are lower than those of plain mineral oil. In particular, compare the higher-temperature trials at each additive level of ZDP with that of plain mineral oil. Also, the friction coefficient shows no change with increasing load except in the case of the 2\% ZDP at $200{ }^{\circ} \mathrm{C}$. At $200{ }^{\circ} \mathrm{C}$, a sudden increase of the friction coefficient during the test coincides with a sharp increase in refractive index. For $1 \% \mathrm{ZDP}$, the friction coefficient is slightly lower than for the $2 \% \mathrm{ZDP}$ case. As an example, the friction coefficient at $150^{\circ} \mathrm{C}$ is lower than that at $100{ }^{\circ} \mathrm{C}$ and decreases with increasing load. For $0.5 \% \mathrm{ZDP}$ at $150{ }^{\circ} \mathrm{C}$, the friction is high, and thinning of the film is accompanied by an increase in refractive index. Consequently, initiation of scuffing occurs.

The results described so far confirm that boundary film formation, composition and friction behavior depend strongly on temperature, although the relationship is not direct or monotonic. Consequently, previous roomtemperature results do not accurately predict highertemperature results. For ZDP-containing oil, the thickness and refractive index of the films are greatly influenced by temperature and concentrations of ZDP. In previous work at room temperature, there were only slight differences in the film thickness between the different concentrations of ZDP. However, in the present work at higher temperature, an increasing concentration of ZDP tends to promote faster and thicker film formation.

Mineral oil with $2 \%$ ZDP, having more ZDP than the other lubricants tested, is expected to have higher reactivity as well. Experiments have shown that the boundary films grow faster and thicker in the case of $2 \% \mathrm{ZDP}$ than for either $1 \%$ or $0.5 \% \mathrm{ZDP}$. However, a subsequent rapid decay of the films with increasing load indicates that the films from $2 \%$ ZDP are less durable than those of $1 \% \mathrm{ZDP}$. The frequent fluctuation of the film thickness during the test may indicate a competitive balance between re-growth of film, as a consequence of the high reactivity of the ZDP, and film loss by sliding, as a consequence of a decrease in the durability of the film. Therefore, the very thin film at $200{ }^{\circ} \mathrm{C}$ may indicate that the removal rate of the film exceeds the film formation rate, even at the beginning of sliding. For $1 \% \mathrm{ZDP}$, the lubricant has a lower reactivity than $2 \% \mathrm{ZDP}$, so it exhibits slower film growth at the beginning of sliding. However, the film remains relatively thick, and produces low friction even at higher loads, indicating that the film is more durable and effective than that of $2 \%$ ZDP. For $0.5 \%$ ZDP, the film appears to be less durable and does not contribute to reducing the friction and preventing severe wear at high load.

From the above results, we suggest that there are certain optimum operation conditions for ZDP-containing lubricants, such as optimum additive concentration and oil temperature. For example, for a given temperature, an optimum concentration exists at which the boundary film becomes thick and durable, and functions as a protective film, producing the minimum friction and wear. In this experiment, that optimum concentration is near $1 \% \mathrm{ZDP}$.

\subsection{Dual-layer model}

In order to investigate the effect of temperature on the composition and structure of the boundary films, 
a dual-film model is used. In the previous experiments, Çavdar and Ludema [16] considered that the boundary films formed at room temperature are composed of two layers of compound: an organo-iron compound (OIC), having a refractive index between 1.5 and 2.5 with zero absorption, below which lies a layer of a mixture of iron oxide, metallic iron and iron-carbon compound (OMM), having a refractive index of 4.2 with zero absorption. They proposed this dual-layer model for simplicity in using the ellipsometer. Results from several chemical analysis instruments including XPS, Forward-Recoil Spectroscopy (FRS) and Fourier Transform Infrared Spectroscopy (FTIR) confirmed the same general conclusion, but indicated a gradual change in composition rather than a step change.

For plain mineral oil, the changes in thickness of each layer from the dual-layer model are shown in Fig. 7. The organo-iron compound (OIC) becomes thinner with increasing temperature and at some point completely vanishes. This suggests that OIC is mechanically weak. The oxide and metallic iron compound (OMM) shows negligible changes in thickness with increasing temperature, except that it gradually decreases in thickness near the end of trial (maximum load). The OMM appears to be very stable and strong, and therefore is
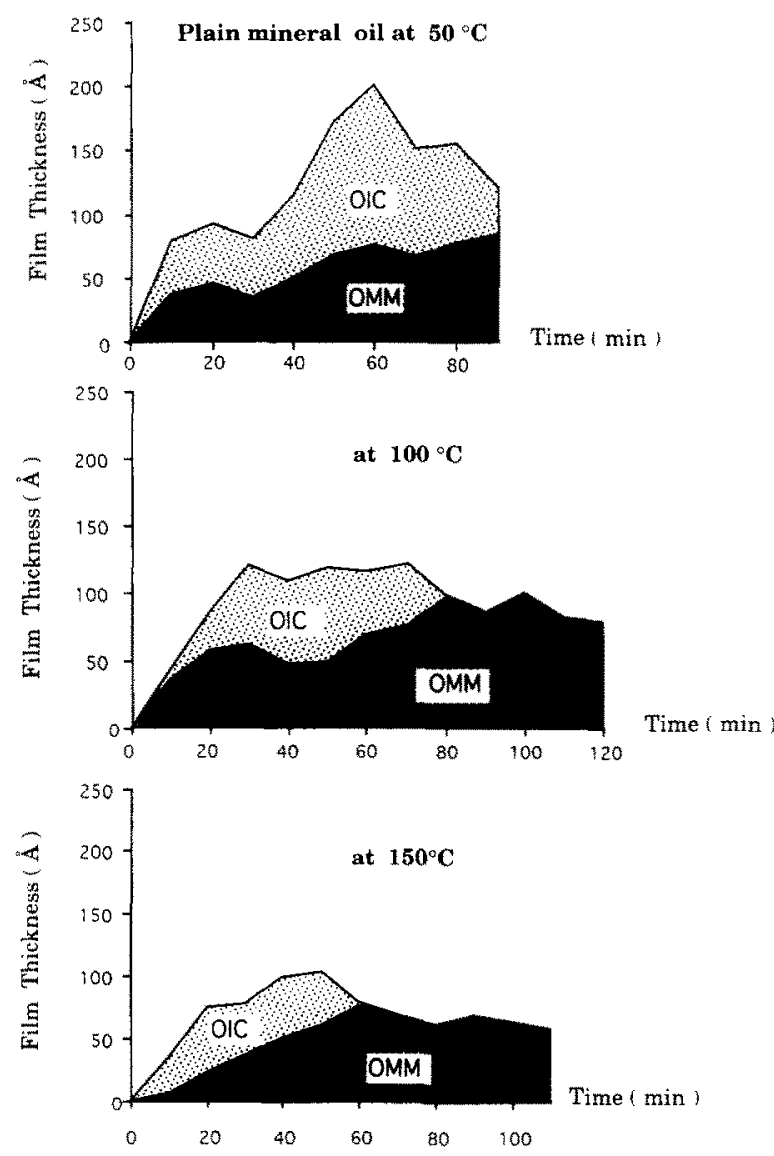

Fig. 7. Change in ellipsometric film thickness with applied load and temperature as obtained from a dual-layer model. not influenced by moderate increases in temperature and load.

For ZDP-containing oil, the ellipsometric results obtained from application of the dual-layer model show that the OIC is much thicker than the OMM. This is seen in the lower average value of refractive index (1.5-2.5) and the lighter color of the films compared to those at room temperature from plain mineral oil and ZDP-containing oil. The overall refractive index of the films at room temperature was between 3 and 4. Additionally, since the OIC is so much thicker than the OMM in these oils, the ellipsometry method may not reliably distinguish the OMM layer. Therefore, in the present experiment, the results obtained from the dual-layer model are not included for the films formed in ZDP-containing oil at high temperatures.

\subsection{Chemical analysis}

The composition of the boundary films formed during sliding was analyzed by XPS, and the results were correlated with the values of refractive index, which were obtained by ellipsometry. In particular, the analyses were conducted for several samples of the films formed in mineral oil with $2 \% \mathrm{ZDP}$ at high temperatures. The chemical analysis was not performed for the films formed in plain mineral oil, since the ellipsometry measurements indicated that the film composition is not greatly changed at higher temperatures compared with that at room temperature. In order to investigate the effects of load and bulk oil temperature on changes in film composition, the samples were prepared with low and high load, and at various temperatures.

XPS surface analysis was performed on the $2 \%$ ZDP wear trials on the wear track at 100,150 and $200{ }^{\circ} \mathrm{C}$, including both high and low load at $150{ }^{\circ} \mathrm{C}$. Table 2 displays the surface atom fraction values for the samples analyzed. Films were observed to contain $\mathrm{Fe}, \mathrm{O}, \mathrm{N}$, $\mathrm{C}, \mathrm{S}, \mathrm{P}$ and $\mathrm{Zn}$. Changes in surface composition of the films can be seen as temperature or load increases. For films formed at $150{ }^{\circ} \mathrm{C}$, the high-load (1101 N) film contains a smaller amount of $\mathrm{Zn}, \mathrm{P}$ and $\mathrm{S}$ than the low-load $(195 \mathrm{~N})$ film. Also, with low load, the film formed at $200^{\circ} \mathrm{C}(265 \mathrm{~N})$ contains a smaller amount of $\mathrm{Zn}, \mathrm{P}$ and $\mathrm{S}$ than that at $150^{\circ} \mathrm{C}(195 \mathrm{~N})$. Note that, as shown in Fig. 4, the $2 \%$ ZDP film formed at 200 ${ }^{\circ} \mathrm{C}$ exhibited scuffing at $328 \mathrm{~N}$, which is the next step

Table 2

Atomic \% summaries for $2 \% \mathrm{ZDP}$-induced films

\begin{tabular}{lcccrrrr}
\hline Specimen & Fe & O & C & N & Zn & P & \multicolumn{1}{c}{ S } \\
\hline $100^{\circ} \mathrm{C}$ at $601 \mathrm{~N}$ & 9.0 & 30.5 & 46.0 & 1.9 & 2.5 & 8.3 & 1.9 \\
$150^{\circ} \mathrm{C}$ at $1101 \mathrm{~N}$ & 2.8 & 32.4 & 47.8 & 2.0 & 4.5 & 8.5 & 2.1 \\
$150^{\circ} \mathrm{C}$ at $195 \mathrm{~N}$ & 4.0 & 35.8 & 34.3 & $<1.0$ & 6.4 & 15.4 & 4.0 \\
$200^{\circ} \mathrm{C}$ at $265 \mathrm{~N}$ & 7.3 & 33.9 & 43.0 & 3.5 & 2.1 & 7.2 & 3.0 \\
\hline
\end{tabular}


load after $265 \mathrm{~N}$. These results may indicate that absence of $\mathrm{Zn}, \mathrm{P}$ and $\mathrm{S}$ elements in the films produces films of low mechanical strength.

Depth profiling was performed on the $2 \%$ ZDP, 150 ${ }^{\circ} \mathrm{C}$ wear trial, which was stopped at $1101 \mathrm{~N}$ load. Table 3 lists the atom fractions for all elements detected, as a function of depth. The sputter rate was determined to be $20.9 \AA \mathrm{min}^{-1}$ as outlined in Section 2 above. The atom fraction of carbon decreases from a maximum of 50 at.\% to 8 at.\% after $4 \mathrm{~min}$ (approximately 80 $\AA$ ) of ion etching. This high concentration of $\mathrm{C}$ on the top layer of the film may be caused from either incompletely removed oil residue or atmospheric contamination (or a combination of the two). The $\mathrm{Fe}$ atom fraction gradually increases along the film thickness, while the $O$ content decreases with depth. Ar observed in the surface spectra originated from implanting of $\mathrm{Ar}^{+}$during ion etching.

These results are compared to the depth-dependent composition of the films formed at room temperature [16]. This is given in Table 4. Compared with the roomtemperature result, at high temperature the concentrations of $\mathrm{O}, \mathrm{C}, \mathrm{Zn}, \mathrm{P}$ and $\mathrm{S}$ in the film are increased, but the concentration of $\mathrm{Fe}$ is decreased. The increase in the content of $\mathrm{P}$ is considerable.

For the $\mathrm{O}(1 \mathrm{~s})$ region of the XPS depth profile, two peaks were observed, which were found to be at ap-

Table 3

Atomic $\%$ in the film formed in mineral oil with $2 \%$ ZDP at 150 ${ }^{\circ} \mathrm{C}, 1101 \mathrm{~N}$

\begin{tabular}{rccrllllllr}
\hline $\begin{array}{l}\text { Etch } \\
\text { cycle }\end{array}$ & $\begin{array}{l}\text { Time } \\
(\mathrm{min})\end{array}$ & $\begin{array}{l}\text { Thickness } \\
(\AA)\end{array}$ & Fe & O & C & Ar & Zn & S & \multicolumn{1}{c}{ P } \\
\hline 1 & 0 & 0 & 2.8 & 32.4 & 47.8 & 0.0 & 4.5 & 2.1 & 8.5 \\
2 & 4 & 84 & 30.7 & 30.4 & 7.6 & 1.6 & 5.9 & 6.6 & 17.1 \\
3 & 8 & 168 & 40.3 & 26.0 & 4.8 & 1.5 & 4.8 & 7.9 & 14.9 \\
4 & 12 & 252 & 45.2 & 25.3 & 7.1 & 1.7 & 4.3 & 5.1 & 11.3 \\
5 & 16 & 336 & 50.3 & 21.3 & 7.1 & 1.3 & 4.6 & 5.3 & 10.2 \\
6 & 20 & 420 & 57.2 & 19.3 & 4.7 & 2.0 & 4.4 & 4.3 & 8.1 \\
7 & 24 & 504 & 56.8 & 15.9 & 7.5 & 0.9 & 2.9 & 4.3 & 11.6 \\
8 & 28 & 588 & 73.6 & 13.6 & 4.1 & 1.6 & 1.8 & 3.9 & 1.5 \\
9 & 32 & 672 & 72.7 & 12.3 & 3.5 & 2.2 & 2.2 & 1.8 & 5.5 \\
10 & 40 & 840 & 73.0 & 10.6 & 6.6 & 3.1 & 2.2 & 2.6 & 1.8 \\
\hline
\end{tabular}

Table 4

Atomic composition of film formed in mineral oil with $2 \%$ ZDP at room temperature $\left(20^{\circ} \mathrm{C}\right.$ ) (reprinted from Çavdar and Ludema [16])

\begin{tabular}{lllllllll}
\hline $\begin{array}{l}\text { Etch } \\
\text { cycle }\end{array}$ & $\begin{array}{l}\text { Time } \\
(\mathrm{min})\end{array}$ & $\begin{array}{l}\text { Thickness } \\
(\AA)\end{array}$ & $\mathrm{Fe}$ & $\mathrm{O}$ & $\mathrm{C}$ & $\mathrm{Zn}$ & $\mathrm{S}$ & $\mathrm{P}$ \\
\hline 1 & 0.5 & $20-30$ & 56.5 & 22.5 & 8.0 & 4.5 & 5.0 & 3.5 \\
2 & 1 & $40-60$ & 72.5 & 15.5 & 3.5 & 2.5 & 2.5 & 3.5 \\
3 & 1.5 & $60-80$ & 79.5 & 12.0 & 3.0 & 1.5 & 2.0 & 2.0 \\
4 & 2 & $80-100$ & 85.0 & 9.0 & 2.0 & 1.5 & 1.5 & 1.0 \\
5 & 2.5 & $100-120$ & 90.5 & 5.0 & 2.0 & 1.0 & 1.0 & 0.5 \\
6 & 3 & $120-140$ & 92.5 & 3.5 & 2.0 & 0.5 & 1.0 & 0.5 \\
\hline
\end{tabular}

proximately $530.3 \mathrm{eV}$ and $531.7 \mathrm{eV} .530 .3 \mathrm{eV}$ is within the binding energy (BE) range of a metal oxide such as $\mathrm{Fe}_{2} \mathrm{O}_{3}$ or $\mathrm{Fe}_{3} \mathrm{O}_{4}$, which possess $\mathrm{BE}$ values of $529.8-530.2 \mathrm{eV}$ [19]. The peak at $531.7 \mathrm{eV}$ is too low to be a purely organic oxygen (these are generally in the range of 532.8-533.7 eV [20]), and may correspond to a material with metal-organic type bonding. Also, the $531.7 \mathrm{eV} \mathrm{BE}$ observed here agrees with $\mathrm{O}(1 \mathrm{~s}) \mathrm{BE}$ values for ferric orthophosphate $(531.7 \mathrm{eV})$ and ferric pyrophosphate $(531.6 \mathrm{eV})$ [11], suggesting that oxygen and iron may be bonded in a manner similar to these compounds.

The $\mathrm{BE}$ values observed for $\mathrm{Zn}$ on the unsputtered surfaces was approximately $1022.5 \mathrm{eV}$, and did not appear to change appreciably with applied load or temperature over the range studied. This $\mathrm{Zn}$ value is consistent with the formation of $\mathrm{Zn}_{3}\left(\mathrm{PO}_{4}\right)_{2} \cdot x \mathrm{H}_{2} \mathrm{O}$ $(1022.6 \mathrm{eV}$ [21]), but a wide variety of other species cannot be ruled out, since the $\mathrm{Zn}$ chemical shift is not large with changes in $\mathrm{Zn}$ chemistry. Indeed, Zn (metal)

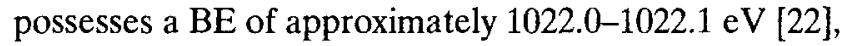
relatively close to the $\mathrm{BE}$ value of the $\mathrm{Zn}$ polyphosphate. Similarly, the $O(1 \mathrm{~s})$ binding energy values mentioned above are consistent with the formation of this polyphosphate [21]. Note that, since $\mathrm{Fe}, \mathrm{C}, \mathrm{S}$ and $\mathrm{P}$ are also present in the tribofilm, the latter material may contain some or all of those elements, and may be a complex mixture.

In order to determine trends in the $O(1 s)$ data as a function of the chemical composition of the film as detected by XPS, the $O(1 \mathrm{~s})$ spectra were peak-fitted to metal oxide and organic oxide, and ratios were calculated. An example of this curve-fitting process is shown in Fig. 8(a). The ratio of the oxide oxygen to metal-organic oxygen as a function of sputter time (depth) is shown in Table 5. Here, the ratio is approximately $1: 3$ and is fairly constant with depth.

The BE value obtained for $S$ on unsputtered wear surfaces was found to be relatively constant in the $162.0-162.3 \mathrm{eV}$ range. This is consistent with an FeStype species (literature $\mathrm{BE}$ values in the range of $161.8-162.5[22,23])$. The literature $\mathrm{BE}$ valuc for $\mathrm{ZnS}$ is somewhat outside of the observed range at approximately $164.2 \mathrm{cV}$ [22]. At higher loads and temperatures, unsputtered wear surfaces also exhibited a peak at about $169.0 \mathrm{eV}$, consistent with the formation of a sulfate species. This result is in qualitative agreement with previous work [23].

It should be noted that conclusions regarding the chemical state of a surface after sputtering can be misleading. The interaction of the $(4 \mathrm{keV})$ ion beam with the sample surface certainly breaks bonds and can alter the chemical state of metals. The sputtering of polymer materials quickly graphitizes the surface, making conclusions about organic bonding difficult. The value of these sputter profiles is in the trend observed 

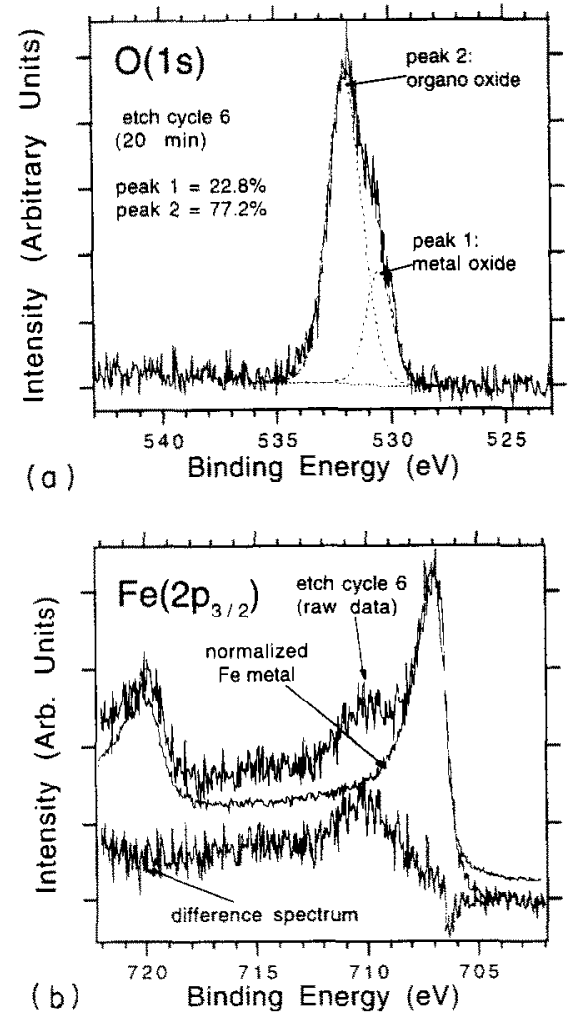

Fig. 8. (a) $\mathrm{O}(1 \mathrm{~s})$ region peak fits by curve-fitting for film formed in mineral oil with $2 \% \mathrm{ZDP}$ at $150{ }^{\circ} \mathrm{C}, 1101 \mathrm{~N}$. (b) $\mathrm{Fe}(2 \mathrm{p})$ region peak fits by difference technique (separation of pure iron and compound iron contribution from the complex iron peak) for film formed in mineral oil with $2 \% \mathrm{ZDP}$ at $150^{\circ} \mathrm{C}, 1101 \mathrm{~N}$.

Table 5

The percentage of pure iron and compound iron from Fe(2p) peaks, and that of oxide oxygen and organic oxygen from $O(1 s)$ peaks for the film formed in mineral oil with $2 \% \mathrm{ZDP}$ at $150^{\circ} \mathrm{C}, 1101 \mathrm{~N}$

\begin{tabular}{|c|c|c|c|c|c|c|}
\hline \multirow{2}{*}{$\begin{array}{l}\text { Etch } \\
\text { cycle }\end{array}$} & \multirow{2}{*}{$\begin{array}{l}t \\
(\min )\end{array}$} & \multirow{2}{*}{$\begin{array}{l}\text { Thickness } \\
(\AA)\end{array}$} & \multicolumn{2}{|c|}{$O(1 s)$ region } & \multicolumn{2}{|c|}{$\mathrm{Fe}(2 \mathrm{p})$ region } \\
\hline & & & $\begin{array}{l}\text { Oxide } \\
\text { oxygen } \\
(\%)\end{array}$ & $\begin{array}{l}\text { Organic } \\
\text { oxygen } \\
(\%)\end{array}$ & $\begin{array}{l}\text { Pure } \\
\text { iron } \\
(\%)\end{array}$ & $\begin{array}{l}\text { Compound } \\
\text { iron } \\
(\%)\end{array}$ \\
\hline 1 & 0 & 0 & 21.4 & 78.6 & 4.3 & 95.7 \\
\hline 2 & 4 & 84 & 23.9 & 76.1 & 12.9 & 87.1 \\
\hline 3 & 8 & 168 & 24.1 & 75.9 & 28.6 & 71.4 \\
\hline 4 & 12 & 252 & 25.1 & 74.9 & 50.4 & 49.6 \\
\hline 5 & 16 & 336 & 22.7 & 77.3 & 64.1 & 35.9 \\
\hline 6 & 20 & 420 & 22.8 & 77.2 & 72.9 & 27.1 \\
\hline 7 & 24 & 504 & 22.9 & 77.1 & 78.6 & 21.4 \\
\hline 8 & 28 & 588 & 24.7 & 75.3 & 80.7 & 19.3 \\
\hline 9 & 32 & 672 & 22.8 & 77.2 & 87.5 & 12.5 \\
\hline 10 & 40 & 840 & 21.8 & 78.2 & 96.8 & 3.2 \\
\hline
\end{tabular}

with depth. In the depth profiles presented here, cach depth point analyzed by XPS has seen the same ion dose (except for the unsputtered surface), so that conclusions from chemical state trends and changes with depth should be valid.

The spectra of the $\mathrm{Fe}(2 \mathrm{p})$ region of the depth profile revealed a complex iron peak. This iron peak is expected to have two major contributors: one is pure iron, and the other is iron in a compound form, either as an oxide or as any other compound. The complex background makes the separation of the pure iron and compound iron peaks in the spectrum difficult. For this reason, a difference technique was used instead of curve-fitting. This procedure may be summarized briefly as follows. First, a spectrum of the steel substrate was acquired from $2640 \mathrm{~s}$ (44 min) sputtering of an area away from the wear scar. This spectrum is considered to be representative of pure Fe standard. Next, a linear background line was fitted for the standard Fe spectrum and each unknown spectrum. The determined background area was then subtracted from each spectrum. After background correction of each spectrum, an Fe standard spectrum was normalized to each unknown spectrum by determining the height of the metal peak in the Fe standard spectrum and the height of the unknown spectrum at the binding energy where the metal peak should occur (approximately $706.9 \mathrm{eV} \mathrm{[22]).}$ The Fe standard spectrum was then multiplied by this normalization factor. An example of this procedure is shown in Fig. 8(b).

The area of the normalized standard spectrum and the unknown spectra were calculated, using the same binding-energy limits of integration. By ratioing, these integrals yield the relative fraction of pure iron and compound iron in the $\mathrm{Fe}$ region, which is shown in Table 5. The amount of pure iron increases gradually with depth, and the amount of compound iron decreases correspondingly. At the tenth cycle of etching, which is $2400 \mathrm{~s}$, a $96.8 \%$ pure iron peak is obtained, indicating that the thickness of the film is almost $840 \AA$. The agreement between the film thickness as determined by ellipsometry (approximately $300 \AA$ ) and by XPS ( 840 $\AA$ or more) is reasonable, considering the errors and assumptions involved for each of the measurement techniques. First, both techniques are sensitive to surface roughness. Second, the ellipsometric value for the film thickness assumes abrupt interfaces between the films and underlying metal. It is evident from the XPS depth profile (see Table 5) that this is not the case, and that the transition from the wear-induced film to the underlying metal is gradual. This can lead to discrepancies between the two methods. The value of these determinations is to observe relative differences as a function of the specific conditions of the wear trials, so that, while absolute agreement is convenient, it is not essential.

The total atom fractions of these peak-fitted constituents in the film can be obtained by multiplying the percentage in Table 5 by the atomic \% value, which is found in Table 3. However, the calculation of the total iron oxide content in the films needs extra work: in order to find the amount of iron compound which is iron oxide, we look at the oxygen amount which is 
in oxide form (in a previous work [13], iron oxide was identified as $\mathrm{Fe}_{3} \mathrm{O}_{4}$ ). The oxide oxygen amount is then multiplied by 0.75 to find the amount of iron which is in oxide form. This is the amount of oxide iron. The sum of the oxide oxygen and the oxide iron gives the total iron oxide percentage. The remainder of the film apart from pure iron and iron oxide is probably in the form of an organo-iron compound. The calculated fractions of these constituents in the film are shown in Table 6.

Near the surface, the film is mainly composed of organo-iron compound. Also, compared with results of Cavdar and Ludema [16] at room temperature (Table 7 ), there is significantly more organo-iron compound in the films formed at high temperature. As discussed already, this result is consistent with the ellipsometric result of a lower refractive index and larger amount of $\mathrm{C}, \mathrm{S}, \mathrm{P}$ and $\mathrm{Zn}$ in the films formed at higher temperature, compared to room temperature. Other researchers $[16,24]$ have stated that, for ZDP-containing oil, $\mathrm{Zn}, \mathrm{P}$ and $\mathrm{S}$ compete with $\mathrm{O}$ in forming reaction films on surfaces, and this consequently reduces the

\section{Table 6}

Total atomic fraction of pure iron, iron oxide and organo-iron compound in the film formed in mineral oil with $2 \% \mathrm{ZDP}$ at 150 ${ }^{\circ} \mathrm{C}, 1101 \mathrm{~N}$ as calculated from Tables 3 and 5

\begin{tabular}{|c|c|c|c|c|c|}
\hline \multirow{2}{*}{$\begin{array}{l}\text { Etch } \\
\text { cycle }\end{array}$} & \multirow{2}{*}{$\begin{array}{l}\text { time } \\
\text { (min) }\end{array}$} & \multirow{2}{*}{$\begin{array}{l}\text { Thickness } \\
(\AA)\end{array}$} & \multicolumn{3}{|c|}{ Constituents of the film } \\
\hline & & & $\begin{array}{l}\text { Pure } \\
\text { iron } \\
(\%)\end{array}$ & $\begin{array}{l}\text { Iron } \\
\text { oxide } \\
(\%)\end{array}$ & $\begin{array}{l}\text { Organo-iron } \\
\text { compound } \\
(\%)\end{array}$ \\
\hline 1 & 0 & 0 & 0.1 & 12.2 & 87.7 \\
\hline 2 & 4 & 84 & 4.0 & 12.7 & 83.3 \\
\hline 3 & 8 & 168 & 11.5 & 11.0 & 77.5 \\
\hline 4 & 12 & 252 & 22.8 & 11.1 & 66.1 \\
\hline 5 & 16 & 336 & 32.2 & 8.5 & 59.3 \\
\hline 6 & 20 & 420 & 41.7 & 7.7 & 50.6 \\
\hline 7 & 24 & 504 & 44.6 & 6.4 & 49.0 \\
\hline 8 & 28 & 588 & 59.4 & 5.9 & 34.7 \\
\hline 9 & 32 & 672 & 63.6 & 4.9 & 31.5 \\
\hline 10 & 40 & 840 & 70.6 & 4.1 & 25.3 \\
\hline
\end{tabular}

Table 7

Total atomic fraction of pure iron, iron oxide and organo-iron compound in film formed in mineral oil with $2 \%$ ZDP at room temperature (reprinted from Çavdar and Ludema [16])

\begin{tabular}{llllll}
\hline $\begin{array}{l}\text { Etch } \\
\text { cycle }\end{array}$ & $\begin{array}{l}\mathrm{t} \\
(\min )\end{array}$ & $\begin{array}{l}\text { Thickness } \\
(\AA)\end{array}$ & $\begin{array}{l}\text { Pure } \\
\text { iron } \\
(\%)\end{array}$ & $\begin{array}{l}\text { Iron } \\
\text { oxide } \\
(\%)\end{array}$ & $\begin{array}{l}\text { Organo-iron } \\
\text { compound } \\
(\%)\end{array}$ \\
\hline 1 & 0.1 & $20-30$ & 39 & 8 & 53 \\
2 & 1 & $40-60$ & 56 & 8 & 36 \\
3 & 1.5 & $60-80$ & 67 & 7 & 26 \\
4 & 2 & $80-100$ & 80 & 6 & 14 \\
5 & 2.5 & $100-120$ & 88 & 4 & 8 \\
6 & 3 & $120-140$ & 91 & 3 & 6 \\
\hline
\end{tabular}

formation of the iron oxide. It may be said that this competing action of $\mathrm{Zn}, \mathrm{P}$ and $\mathrm{S}$ against $\mathrm{O}$ may be more effective at higher temperatures, possibly owing to an increase in chemical reactivity. As temperature increases, the reaction rate of $7 n, P$ and $S$ may be increased much more than that of $O$.

In addition, the films formed at high temperatures are less durable than those at room temperature, even though these films contain a larger amount of $\mathrm{Zn}, \mathrm{P}$ and $S$, which are considered to improve the mechanical property of the film. This may be because either the mechanical strength diminishes as the film thickness increases or the structure of the film changes.

\subsection{Factors controlling wear}

Wear on only the cylinder was measured, since wear on the disk cannot be readily measured. However, wear on the cylinder can provide valuable information about the film on the opposing surface.

Fig. 9(a) shows the changes in wear rate on the cylinder, fluid film thickness and boundary film thickness on the disk during sliding in plain mineral oil at 100 ${ }^{\circ} \mathrm{C}$. The wear rate was calculated as the volume worn from the cylinder, divided by the total sliding distance. The wear scar width of the cylinder was measured by an optical microscope. The fluid film thickness was calculated from the elastohydrodynamic theory, using the equations developed by Pan and Hamrock [25] for line contact. Note that film thicknesses were only es. timated in order to determine if the fluid film is so thick that asperity contact is unlikely.

In Fig. 9(a), the wear rate increases as load increases at the beginning of sliding, accompanied by an increase in the boundary film thickness; shortly after, however, the wear rate levels off while the boundary film remains thick. Beyond a load of $540 \mathrm{~N}$, the wear rate again increases and the boundary film becomes thin. The fluid film thickness is less than the boundary film thickness and is nearly constant with increasing loads. For plain mineral oil at $150{ }^{\circ} \mathrm{C}$, shown in Fig. 9(b), the overall wear rate is much higher than at $100^{\circ} \mathrm{C}$. However, like the $100^{\circ} \mathrm{C}$ case, the wear rate also drops off when the film reaches the maximum thickncss. Subsequently, a sharp increase in wear rate also occurs when the boundary film becomes thin. The fluid film is much thinner than the boundary film.

The case of mineral oil with $2 \% \mathrm{ZDP}$ at $100{ }^{\circ} \mathrm{C}$ is shown in Fig. 10(a). Note that the scale of the vertical axis is three times larger to accommodate the high wear rate. Both the wear rate and boundary film thickness increase sharply at the beginning of sliding. After that, however, the wear rate levels off while the boundary film becomes thin. The fluid film thickness is considered to be the same as that of plain mineral oil, assuming that the small amount of ZDP (2\%) does not appreciably 
Mineral oil at $100^{\circ} \mathrm{C}$

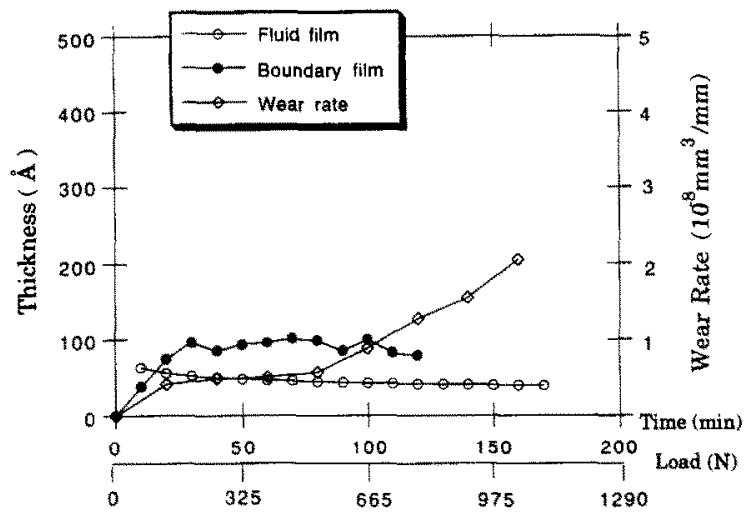

(a)

Mineral oil at $150{ }^{\circ} \mathrm{C}$

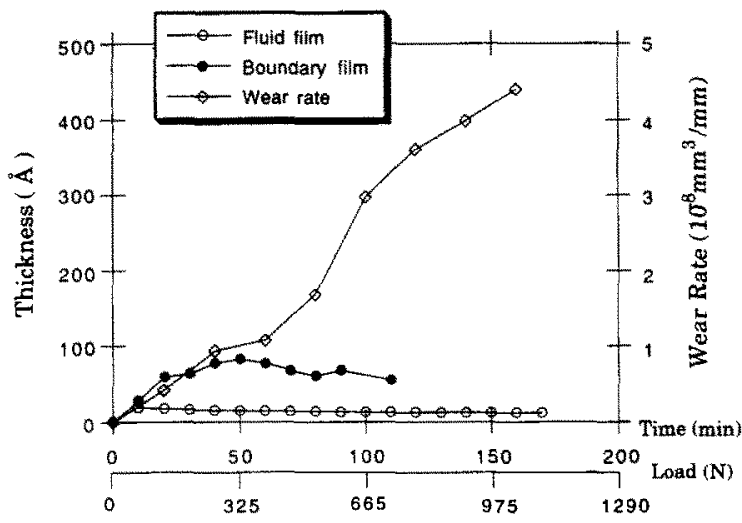

(b)

Fig. 9. Changes in fiuid film thickness, boundary film thickness on the disk, and wear rate on the cylinder in plain mineral oil with increasing loads: (a) at $100^{\circ} \mathrm{C}$; (b) at $150{ }^{\circ} \mathrm{C}$.

influence the fluid film thickness of the base lubricant. Comparing mineral oil with $2 \% \mathrm{ZDP}$ at $150{ }^{\circ} \mathrm{C}$ to that at $100{ }^{\circ} \mathrm{C}$, it is found that, although the wear rate is higher for $150^{\circ} \mathrm{C}$, it exhibits similar trends. In summary, the wear rate at the beginning of sliding for $\mathrm{ZDP}$ containing oil is much higher than that of plain mineral oil. However, after that, the increase of wear rate is much smaller than that of plain mineral oil.

From the above results, the change in wear rate on the cylinder during sliding can be explained mainly in terms of two factors. The first factor is chemical reactivity. As load increases near the beginning of sliding, both wear rate on the cylinder and film growth on the disk increase linearly with time, and the rate of increase depends on the chemical reactivity. The second factor relates to the properties of the boundary film on the disk. These properties include the composition and thickness as well as the mechanical properties of the film. Generally, a thick boundary film on the disk tends
Mineral oil with $2 \%$ ZDP at $100{ }^{\circ} \mathrm{C}$

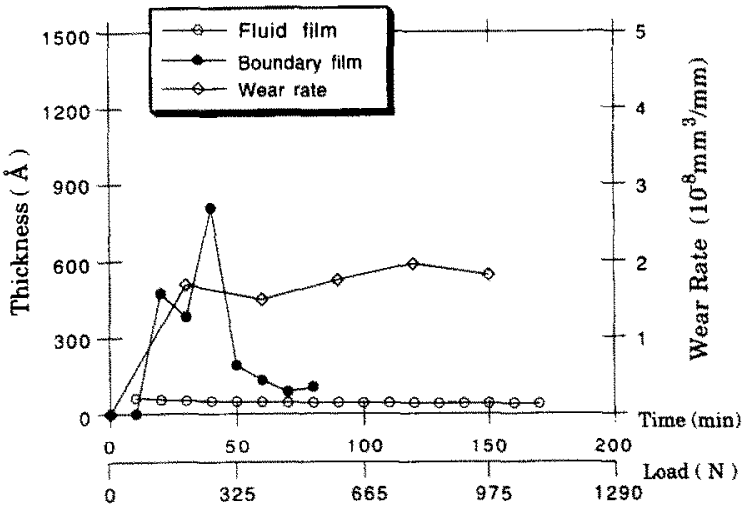

(a)

Mineral oil with $2 \%$ ZDP at $150{ }^{\circ} \mathrm{C}$

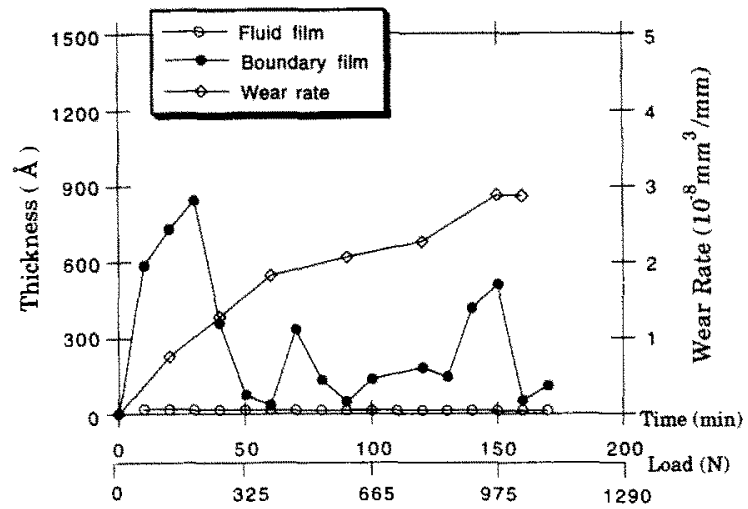

(b)

Fig. 10. Changes in fluid film thickness, boundary film thickness on the disk, and wear rate on the cylinder in mineral oil with $2 \% \mathrm{ZDP}$ with increasing loads: (a) at $100^{\circ} \mathrm{C}$; (b) at $150^{\circ} \mathrm{C}$.

to decrease wear on the cylinder. The composition of the films, however, appears to play the more important role in wear behavior. For plain mineral oil at $100^{\circ} \mathrm{C}$ and $150^{\circ} \mathrm{C}$, a sharp increase in the wear rate at higher loads coincides with the near-disappearance of an organo-iron compound (OIC) in the film (see Fig. 7). This indicates that organo-iron compound in the film is soft and effective in reducing wear of the cylinder, by covering the OMM.

For ZDP-containing mineral oil, the higher reactivity of the lubricant causes more initial wear on the cylinder than does plain mineral oil. Once a film is formed on the disk, the thick film, mainly composed of soft and durable organo-iron compound containing $\mathrm{Zn}, \mathrm{P}$ and $S$, will reduce the wear rate significantly. Even though this film is removed under the conditions of higher load, it will be re-formed more quickly than that of plain mineral oil. By contrast, the organo-iron compound from plain mineral oil is very weak and is easily rubbed 
off even at low loads. Under severe operating conditions, the ZDP-induced films may prevent or delay wear more effectively than the films formed in plain mineral oil. The anti-wear properties of the films formed from ZDP additives have been suggested by several researchers $[12,14]$.

Additionally, it appears that the thickness of the fluid film does not play an important role in the boundary film formation and wear rate during sliding. This is because the fluid film is very thin compared with the boundary film at higher temperature, and changes in the fluid film thickness with increasing load are very small.

\section{Discussion}

Temperature has a major influence on many aspects of tribological behavior on the contact. For this step load test, the increase of both the interface temperature and the bulk oil temperature with increasing load will eventually influence the system in three ways during sliding.

First, there will be an increase in chemical reactivity of the system. As the temperature increases, the reactants or additives in the lubricant compete with each other to form various films at different rates. Second, there will be a decrease in fluid-film thickness owing to a decrease of fluid viscosity. The thinner the fluid film, the greater is the chance that asperity contact will occur, leading to more wear. Third, there will be changes in the chemical composition and properties of the boundary film, including its durability. Alterations in the boundary film chemical composition may affect its mechanical properties.

Even though these facts have been provided or suggested earlier by several other researchers, so far there have been no theories which describe the influence of ambient and transient temperature on boundary film formation, much less the influence of the mechanical action of sliding. This is due to the complexity of the phenomena and lack of proper instrumentation.

The present experiment, however, has produced results which suggest the following model of one mechanism of boundary film formation and loss for a given lubricant and sliding system. As temperature increases, chemical reactivity causes the film formation rate to increase, while the film removal rate increases owing to (a) the decrease in durability of the boundary film and (b) the reduction of hydrodynamic fluid-film thickness which is caused by decreasing viscosity of the lubricant. There should be a balance between these two competing mechanisms, and this balance appears to be reflected in the boundary film thickness. Apparently, as shown in Fig. 11(a), when formation rate exceeds removal rate, the film grows, but when removal
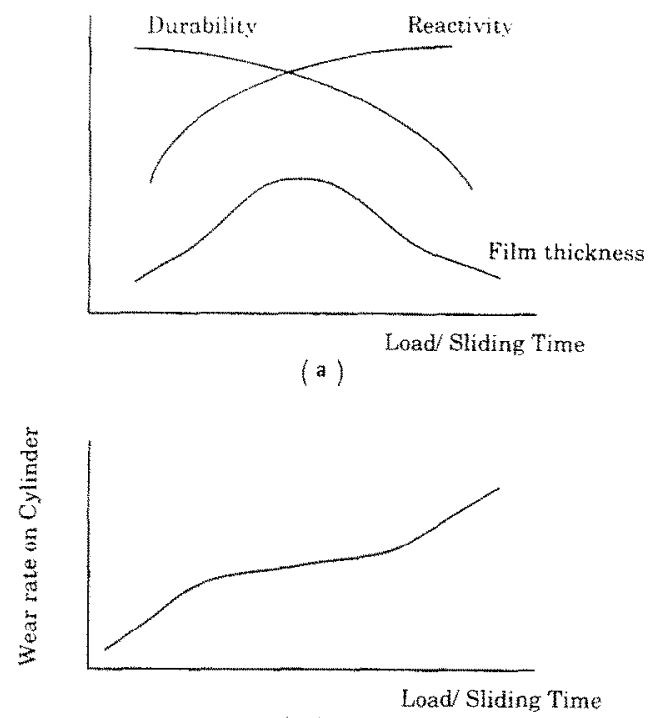

(b)

Fig. 11. (a) Model of the mechanism of boundary film formation. (b) Model of dependence of wear rate on applied load (time).

rate exceeds formation rate, the boundary film thins and eventually vanishes.

At low bulk oil temperatures, the reactivity of the lubricant allows formation of a thin, durable film. As bulk temperature increases over a moderate range, greater reactivity allows the growth of a thicker film; because of lower durability, however, the film begins to diminish above some load. At higher temperature, the removal of the film exceeds the film formation rate; the film remains thin and produces high friction and wear, leading to scuffing even at low load.

From the data on cylinder wear, a model curve for wear rate vs. load was made (Fig. 11(b)). The change in wear rate with increasing load can be explained as consisting of three steps: (a) as load increases at the beginning of sliding, the boundary film thickness on the disk and the wear on the cylinder increases linearly with time, and the rate of increase depends on the chemical reactivity, (b) once the film on the disk grows to nearly the maximum thickness, the thick film prevents severe wear on the cylinder, so that the wear rate drops on. At this stage, wear on the cylinder will be governed by the thickness and other properties of the boundary film, and (c) as load increases further, the film on the disk begins to rub off. Consequently, the film cannot protect the metallic contacts as effectively, and wear rate of the cylinder increases again.

A model curve for friction behavior is more difficult to construct, because its behavior does not follow a consistent pattern of change with load, even though friction generally increases as bulk oil temperature increases. 


\section{Conclusions}

1. The performance of many liquid lubricants is closely associated with boundary film forming ability. Formation and loss of the boundary film are determined by a competition between the opposing processes of chemical reactivity and mechanical removal of the film. As the temperature of a given sliding system is increased, chemical reactivity increases the film formation rate, while the film removal rate increases because of:

(a) the decrease of durability of the boundary film, and

(b) the reduction of hydrodynamic fluid film thickness caused by decreasing viscosity of the lubricant. Of these two dependencies, (a) is thought to predominate.

2. The boundary films that form on steel consist of a film of oxide and metallic compound (OMM) covered by an organo-iron compound (OIC). OMM and OIC are each effective in preventing scuffing. Their relative effectiveness depends on temperature and composition.

3. For the films formed in ZDP-containing mineral oil, as temperature increases, there is a great increase in amount of organo-iron compound. Higher concentration of ZDP results in a faster film formation rate. Of the concentrations of ZDP tested at 150 ${ }^{\circ} \mathrm{C}(0.5,1$ and $2 \%)$, the addition of $1 \%$ ZDP provides the most durable film, which produces the lowest friction and minimizes the probability of scuffing.

4. When a cylinder slides against a flat disk, the initial cylinder wear rate is high where chemical reactivity is high. Once the boundary film on the disk grows to nearly the maximum thickness, however, the thick film on the disk prevents further increase of wear. In particular, a film of organo-iron compound above the OMM gives lower cylinder wear than a film of only OMM.

\section{References}

[1] E.S. Forbes and A.J.D. Reid, Liquid phase adsorption/ reaction studies of organo-sulfur compounds and their loadcarrying mechanism, ASLE Trans., 16 (1973) 50-60.

[2] T. Sakamoto, H. Uetz, J. Fohl and M.A. Khosrawi, The reaction layer formed on steel by additives based on sulfur and phosphorus compounds under conditions of boundary lubrication, Wear, 77 (1982) 139-157.

[3] S. Jahanmir, Wear reduction and surface layer formation by a ZDDP additive, J. Tribol, 109 (Oct. 1987) 557-586.
[4] T. Sakurai and K. Sato, Chemical reactivity and load-carrying capacity of lubricated oils containing organic phosphorus compounds, ASLE Trans., 13 (1970) 252-261.

[5] S. Plaza, The adsorption of zinc dibutyldithiophosphates on iron and iron oxide powders, ASLE Trans., 30 (1987) 233-240.

[6] F.T. Barcroft, R.J. Bird, J.F. Hutton and D. Park, The mechanism of action zinc thiophosphates as extreme pressure agents, Wear, 77 (1982) 355-384.

[7] D. Cooper and J.L. Sullivan, The effect of additive concentration on the wear and friction of low alloy steel under conditions of boundary lubrication, Wear, 131 (1989) 283-301.

[8] B.A. Baldwin, Relationship between surface composition and wear: an X-ray photoelectron spectroscopic study of surfaces tested with organosulfur compounds, ASLE Trans., 19 (1976) 335-344.

[9] D. Godfrey, Chemical changes in steel surfaces during extreme pressure lubrication, ASLE Trans., 5 (1962) 57-66.

[10] B.A. Baldwin, Chemical characterization of wear surfaces using X-ray Photoelectron Spectroscopy, ASLE Trans., 32 (1975) 125-130.

[11] R.J. Bird and D. Galvin, The application of Photoelectron Spectroscopy to the study of E.P. films on lubricated surfaces, Wear, 37 (1976) 143-167.

[12] R.C. Watkins, The antiwear mechanism of ZDDP's, Part II, Tribol. Intl. (Feb. 1982) 13-15.

[13] S.C. Kang and K.C. Ludema, The breaking-in of lubricated surfaces, Wear, 108 (1986) 375-384.

[14] J.M. Palacios, Films formed by antiwear additives and their incidence in wear and scuffing, Wear, 114 (1987) 41-49.

[15] P.V. Kotvis, L. Huezo, W.S. Millman and W.T. Tysoe, The surface decomposition and extreme-pressure tribological properties of highly chlorinated methanes and ethane on ferrous surfaces, Wear, 147 (1991) 401-419.

[16] B. C.avdar and K.C. Ludema, Dynamics of dual film formation in boundary lubrication of steels, Parts $1,11, \mathrm{II}$, Wear, 148 (1991), 305-361.

[17] P.S. Hauge, Mueller Matrix Ellipsometry with imperfect compensators, J. Opt. Soc. Am., 68(I1) (1978) 1519-1528.

[18] D.A. Ramsey, Thin film measurements on rough substrates using Mueller Matrix Ellipsometry, Ph.D. Thesis, University of Michigan, Ann Arbor, MI, 1985.

[19] N.S. McIntyre and D.G. Zetaruk, X-Ray photoelectron studies of iron oxides, Anal. Chem., 49 (Nov. 1977) 1521-1529

[20] G.P. Lopez, D.G. Castner and B.D. Ratner, XPS O 1s binding energies for polymers containing hydroxyl, ether, ketone, and ester groups, Surf. Int. Anal., 17 (1991) 267-272.

[21] E.C. Onyiriuka, Zinc phosphate glass surfaces studied by XPS, J. Non-Cryst. Solids, 163 (1993) 268-273..

[22] C.D. Wagner, W.M. Riggs, L.E. Davis, J.F. Moulder and G.E. Mullinberg, Handbook of $X$-ray Photoelectron Spectroscopy, Perkin-EImer Co., Physical Electronics Division, Eden Prairie, MN, 1979.

[23] K.L. Rhodes and P.C. Stair, The surface chemistry of zinc dialkyldithiophosphate, an antiwear additive, on oxidized iron and steel foils, J. Vac. Sci. Technol. $A, \sigma(3) 1988$ 971-974..

[24] P.A. Willermet, L.R. Mahoney and C.M. Haas, The effects of antioxidant reactions on the wear behavior of a zinc dialkyldithiophosphate, ASLE Trans., 22 (1979) 301-306.

[25] P. Pan and B.J. Hamrock, Simplc formulas for performance parameters used in elastohydrodynamically lubricated line contacts, ASME Trans., 111 (Apr. 1989) 246-251. 